\title{
RELACIONES ENTRE LA LUZ, LOS PIGMENTOS FOTOSINTETICOS Y EL FITOPLANCTON EN LA ALBUFERA DE VALENCIA, LAGUNA LITORAL HIPERTROFICA
}

\author{
Miracle, M.R.*; J.M. Soria; E. Vicente ${ }^{* *}$ y S. Romo \\ * Departamento de Ecologia. Facultad de Ciencias Biológicas. Universidad de Valencia \\ ** Departamento de Microbiología. Facultad de Ciencias Biológicas. Universidad de Valencia \\ Burjasot (Valencia)
}

Palabras clave: Hypertrophic lakes, coastal lagoons, cyanobacteria-eutrophication.

\author{
ABSTRACT \\ RELATIONS BETWEEN LIGHT, PHOTOSINTHETIC PIGMENTS AND PHYTOPLANKTON \\ IN THE ALBUFERA OF VALENCIA, AN HYPERTROPHIC COASTAL LAGOON
}

\begin{abstract}
Samples were taken from eight sites of the Albufera of Valencia during an annual cycle. All the measured parameters evidenciate the extreme hypertrophy of the system. Secchi disk depth is around $0.2 \mathrm{~m}$ and chlorophyll maxima as high as $700 \mathrm{mg} / \mathrm{m}^{3}$. A relation between Secchi disk and light extinction has been estimated by regression, giving a factor of 1.54 . The $\mathrm{pH}$ values are very high (maximum of 9.9) and Eh very low, between 240 and $400 \mathrm{mV}$ in surface waters. The spatio-temporal distribution of the physicochemical parameters follows the pattems of water circulation in the Albufera, in great part, controled by man for ricefields management.

The high eutrophy of this lagoon is evidencied also by the dominance of cyanobactenaand bacteria, mainly sheated, glinding and budding and appendaged bacteria, in the plankton; many of these bacteria are frequent in waste waters. The most abundant cyanobacteria are those of the Oscillatoria redekei group. The northem sampling sites are differenciated from the rest of the Albufera in the proportion of the various algal groups, with a lower representation of bacteria and cyanobactena in favor of a higher diatom abundance.
\end{abstract}

\section{INTRODUCCION}

La Albufera de Valencia es una laguna litoral situada en la costa mediterránea, $10 \mathrm{~km}$ al sur de la ciudad de Valencia. Su extensión aproximada en la actualidad es de $20 \mathrm{~km}^{2}$. Su profundidad media es de 1 $\mathrm{m}$. Ocupa la parte central de una amplia zona húmeda que se extiende entre los ríos Turia y Júcar, con una extensión aproximada de $223 \mathrm{~km}^{2}$; en su mayor parte dedicada al cultivo del arroz. La comunicación de la Albufera con el mar se lleva a cabo por tres canales o «golas» donde el flujo de agua es regulado por compuertas que mantienen su nivel en los valores mas adecuados para el cultivo del arroz (Roselló, 1979). Al oeste de la zona húmeda se sitúa un cordón de poblaciones que suman cerca de 250.000 habitantes y unas 4.000 industrias (censo de 1985), cuyas

Limnética 3: 25-34 (1987)

(C) Asociación Española de Limnologia, Madrid. Spain aguas residuales se vierten sin depurar a cauces naturales pertenecientes a la cuenca hidrográfica de la Albufera. Los aportes hídricos llegan a la Albufera por numerosas acequias procedentes de los nos Turia y Júcar, y por algunos barrancos naturales. Si bien la parte norte de la zona húmeda era anteriormente abastecida por el caudal del Turia, en la actualidad y debido al trasvase de aguas del río Júcar al Tuna, los aportes en esta zona corresponden a aguas mezcladas de ambos. Las zonas oeste y sur se surten exclusivamente de las aguas del Júcar. Entre los principales aportes de agua a la Albufera destacaremos: El Barranco de Chiva o de Massanassa, con aguas residuales urbanas e industriales sin depurar; las acequias de Silla, la Foia y el Senyoret, con aguas residuales fundamentalmente urbanas y las acequias de Overa y Dreta, con aguas agrícolas (fig. 1). A pesar de su ex- 


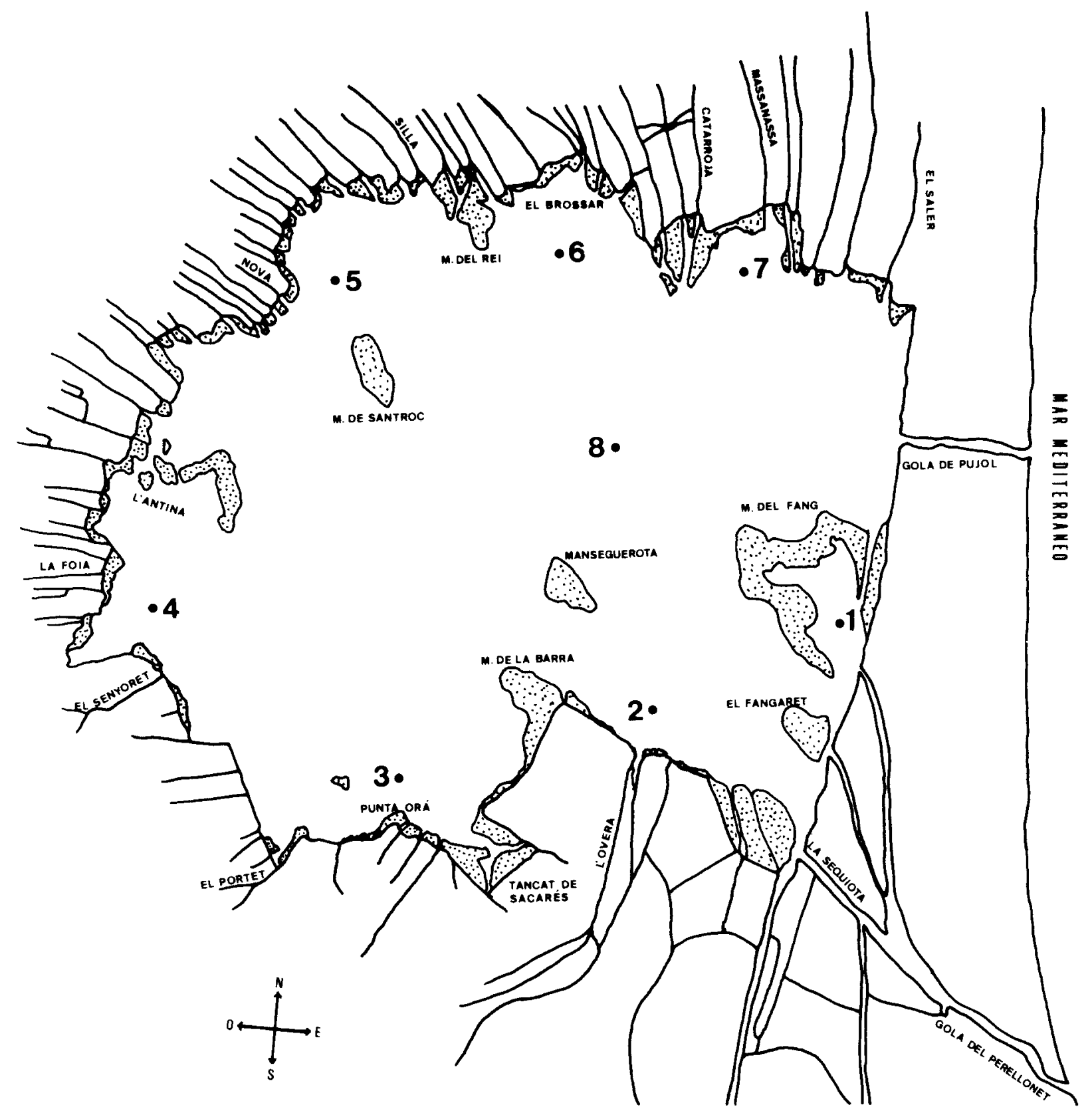

Figura 1.- Mapa de la Albufera de Valencia con indicación de las principales acequias y puntos de muestreo(1-8). Albufera of Valencia map indicating the sampling stations (1-8).

tensión e importancia, no existen otros estudios sobre el fitoplancton mas que los efectuados por los mismos autores; la variación estaciona1 del fitoplancton en un punto de la laguna durante los años 1980-81 fue resumida por García et al, (1984) y las características fisicoquímicas durante la misma época por Serra et al.
(1984). Visto el interés de la sucesión fitoplanctónica y la heterogeneidad espacial de la Albufera, en los años 1982-83 se efectuó un estudio que comprendía ocho estaciones de muestreo distribuidas por toda su superficie. Un avance de sus resultados se describe en Miracle et al. (1984) y Oltra y Miracle (1984). El pre- 


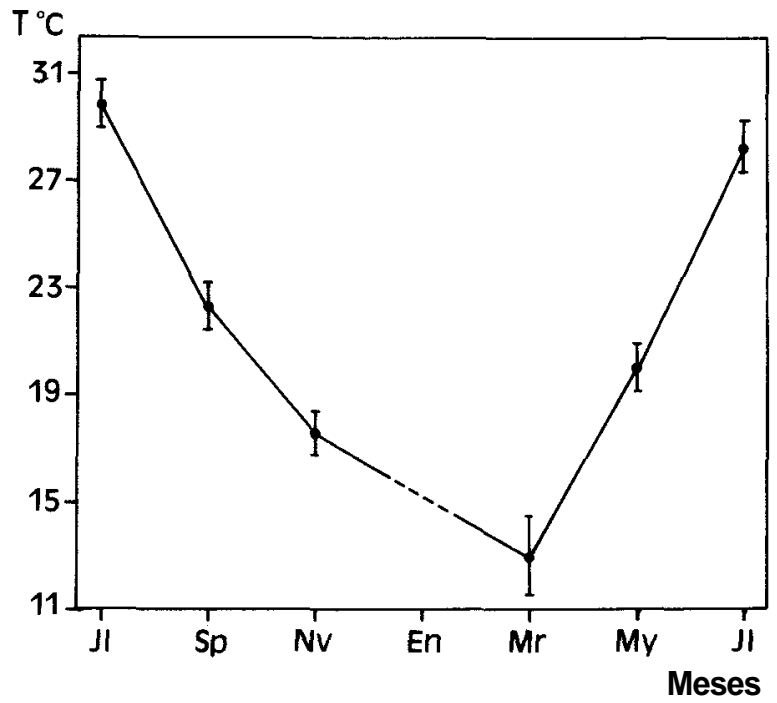

Figura 2.- Distribución temporal de la temperatura; media conjunta de la laguna y desviación típica para los diferentes puntos de muestreo.

Temperature temporal distribution. Averaged temperature of the lagoon and standard deviation for the different sampling stations.

sente estudio se centra en la presentación de unas generalizaciones sobre la distribución de diferentes parámetros del medio en relación con los organismos del fitoplancton, destacando el papel de las Cianobacterias y las bacterias filamentosas, absolutamente dominantes en esta laguna hipertrófica.

\section{METODOS}

El muestreo de la Albufera se realizaba recorriendo sucesivamente siete puntos del perímetro de la laguna y uno en el centro, que pretendían cubrir su heterogeneidad. Los muestreos se realizaron los meses de julio, septiembre y noviembre de 1982 y marzo, mayo y julio de 1983 .

La conductividad, salinidad y temperatura se midieron con un salinómetro YSI mod. 33, expresándose los valores como sus correspondientes a $25^{\circ} \mathrm{C}$. El $\mathrm{pH}$ y el potencial de oxidorreducción se determinaron «in situ» con un pHmetro portátil Radiometer 80. Se tomaron medidas directas de la penetración luminosa con un radiómetro Crump. Sci. Ins. mod. 550, determinándose además la transparencia del agua con el disco de Secchi, calculando posteriormente el coeficiente de extinción para cada punto de muestreo (Wetzel y Likens, 1979).

Se tomaron muestras de agua a $0.5 \mathrm{~m}$ de profundi- dad con una botella hidrográfica de Ruttner de 2.61 de capacidad. De esta muestra se separaban diferentes fracciones. Una de éstas, fijada con lugol, se utilizó para el recuento e identificación del fitoplancton (Huber-Pestalozzi, 1938-1983; Desikachary, 1959; Germain, 1981). Otra parte se recogió para la cuantificación de pigmentos fotosintéticos; para ello, se filtraron $50 \mathrm{ml}$ de muestra a través de discos de fibra de vidrio Whatman GF/F y se extrajeron los pigmentos durante $24 \mathrm{~h} \mathrm{a}-20^{\circ} \mathrm{C}$ con $5 \mathrm{ml}$ de una mezcla $1: 1 \mathrm{de}$ acetona $90 \%$ y DMSO (Shoaf y Lium, 1976). Su contenido en clorofila, feofitinas y carotenoides se valoró espectrofotométricamente según Lorenzen (1967) y Strickland y Parsons (1972).

\section{RESULTADOS Y DISCUSION}

Los resultados ponen de manifiesto una heterogeneidad espacial bastante marcada en la Albufera, puesto que, como se ha dicho, recibe aportes de dos cuencas fluviales distintas cuyas acequias finales conducen aguas de diferentes calidades. La distribución de los parámetros limnológicos está también muy influenciada por la manipulación humana de la Albufera. La apertura de las compuertas origina una circulación del agua que delimita zonas bien diferenciadas, como la del noroeste y determina una variación estacional importante, con dos periodos de máximo flujo de agua en la Albufera: 1) en invierno-primavera (enero a abril), momento del laboreo y siembra del arroz, y 2) a finales de verano (septiembre y octubre), cuando se recolecta el arroz. Entre ellos hay dos periodos de mínima renovación del agua, coincidiendo con el periodo en que las compuertas permanecen cerradas. A esto hay que añadir la catastrófica inundación de finales de octubre de 1982, que supuso una renovación importante de las aguas en la Albufera.

\section{Temperatura y salinidad}

La temperatura osciló durante el periodo estudiado entre $11^{\circ} \mathrm{C}$ en marzo y $30^{\circ} \mathrm{C}$ en julio (fig. 2), siendo poco importantes las diferencias entre las distintas estaciones de muestreo. La salinidad presentó valores entre 0.5 por mil en noviembre y 2.8 por mil en julio en los puntos del norte. La distribución de la conductividad (fig. 3) presenta un gradiente de norte a sur con variaciones en la zona intermedia de aguas más estables. La variación temporal se caracteriza por valores bajos de conductividad durante los periodos en los que las compuertas están abiertas y existen aportes de agua fluvial (septiembre-octubre, enero-abril). Como situación especial, en noviembre de 1982, se dieron los valores mínimos de conductividad, debidos 


\begin{tabular}{|c|c|c|c|c|c|c|c|c|c|c|c|}
\hline \multicolumn{2}{|c|}{$\begin{array}{c}\text { MUESTRA } \\
\text { punto hora }\end{array}$} & $\begin{array}{l}\text { Secchi } \\
\text { (D) } \mathrm{m}\end{array}$ & $\begin{array}{l}\text { Coef. } \\
\text { ext }(n)\end{array}$ & $\begin{array}{l}\text { Prof }\langle\mathrm{m}\rangle \\
1 \% \operatorname{luz}\end{array}$ & $\begin{array}{c}\text { Clor.a } \\
\mu g / 1\end{array}$ & $\begin{array}{r}\text { Indice } \\
433 / 665\end{array}$ & Oxígeno & $\begin{array}{l}\text { geno } \\
\text { \%sat. }\end{array}$ & $\mathrm{pH}^{\mathrm{H}}$ & \multicolumn{2}{|c|}{$\begin{array}{l}\text { Eh } I . D . \\
m v \text { bit/ind }\end{array}$} \\
\hline \multicolumn{12}{|c|}{$27 \mathrm{jul} 1982$} \\
\hline 1 & $11: 00$ & 0.25 & 6.2 & 0.74 & $470 \quad 447$ & 2.03 & 6.1 & 81 & 9.1 & 264 & 2.6 \\
\hline 3 & $10: 00$ & 0.28 & 5.5 & 0.84 & 315308 & 2. 12 & 13.3 & 177 & 8.9 & 263 & 2.3 \\
\hline 4 & $9: 00$ & 0.22 & 7.0 & 0.66 & $444 \quad 433$ & 2.11 & 7.5 & 99 & 8.8 & 255 & 2.1 \\
\hline 5 & $8: 30$ & 0.22 & 7.0 & 0.66 & 532489 & 2.14 & 5.4 & 71 & 9.5 & 241 & 1.9 \\
\hline 7 & $7: 15$ & 0.20 & 7.7 & 0.60 & $494 \quad 440$ & 2.04 & 6.1 & 78 & 8,4 & 270 & 3.3 \\
\hline 8 & $11: 45$ & 0.25 & 6.2 & 0.74 & 503477 & 2.12 & 5.8 & 76 & 9.3 & 298 & 2.4 \\
\hline \multicolumn{12}{|c|}{21 sep 1982} \\
\hline 1 & $12: 00$ & 0.34 & 4.5 & 1.02 & 246217 & 2.01 & 9.7 & 113 & 8.9 & 341 & 3.1 \\
\hline 3 & $8: 20$ & 0.28 & 5.5 & 0.84 & 378339 & 1.98 & 9.9 & 110 & 8.8 & 315 & 3.2 \\
\hline 4 & $9: 25$ & 0.32 & 4.8 & 0.96 & 396361 & 1.93 & 9.3 & 106 & 9.1 & 321 & 3.3 \\
\hline 5 & $10: 10$ & 0.31 & 5.0 & 0.92 & 341289 & 2.63 & 12.2 & 139 & 9.0 & 322 & 3.6 \\
\hline 7 & $11: 00$ & 0.17 & 9.1 & 0.51 & $766 \quad 611$ & 2.15 & 15.5 & 181 & 9.3 & 331 & 3.0 \\
\hline 8 & $11: 30$ & 0.37 & 4.2 & 1.10 & 387383 & 2.00 & 11.2 & 131 & 9.2 & 321 & 3.0 \\
\hline \multicolumn{12}{|c|}{4 nov 1982} \\
\hline 1 & $13: 10$ & 0.22 & $6.1 \%$ & $0.75 *$ & 123117 & 2.06 & 12.2 & 128 & 8.6 & 371 & 2.6 \\
\hline 3 & $9: 25$ & 0.19 & $9.5 \%$ & $0.48 \%$ & 180172 & 2.03 & 9.2 & 94 & 8.2 & 394 & 2.7 \\
\hline 4 & $10: 40$ & 0.21 & $7.9 \%$ & $0.58 \%$ & 317297 & 2.08 & 9.8 & $10 i$ & 8.1 & 385 & 2.9 \\
\hline 5 & $11: 15$ & 0.21 & $7.5 \%$ & $0.61 \%$ & $276 \quad 258$ & 2.06 & 11.9 & 122 & 8.2 & 369 & 2.8 \\
\hline 7 & $12: 15$ & 0.21 & $8.3 \%$ & $0.55 \%$ & 184169 & 2.12 & 5.0 & 53 & 7.7 & 377 & 3.4 \\
\hline 8 & $12: 40$ & 0.20 & $8.4 \%$ & $0.55 *$ & 218208 & 2.05 & 11.5 & 123 & 8.9 & 370 & 2.2 \\
\hline \multicolumn{12}{|c|}{17 mar 1983} \\
\hline 1 & $9: 00$ & 0.17 & $7.7 \%$ & 0.6 & 435420 & 2.16 & - & - & 9.0 & 373 & 2. \\
\hline 3 & $10: 00$ & 0.18 & 7.8 & $0.59 \%$ & 518503 & 2.11 & - & - & 9.2 & 365 & 3.0 \\
\hline 4 & $10: 45$ & 0.21 & $7.2 \%$ & $0.68 \%$ & 577548 & 2.12 & - & - & 9.3 & 384 & 3.3 \\
\hline 5 & $10: 30$ & 0.23 & $6.9 \%$ & $0.67 \%$ & 740701 & 2.15 & - & - & 9.8 & 316 & 3.5 \\
\hline 7 & $12: 10$ & 0.18 & $9.0 \%$ & $0.51 \%$ & 628604 & 2.07 & - & - & 9.2 & 395 & 3.4 \\
\hline 8 & $12: 40$ & 0.21 & $7.5 \%$ & $0.61 \%$ & 635618 & 2.06 & - & - & 9.2 & 361 & 3.4 \\
\hline \multicolumn{12}{|c|}{13 may 1983} \\
\hline 1 & $8: 30$ & 0.20 & 6.61 & $0.70 \%$ & 344350 & 2.10 & 9.8 & 105 & 9.4 & 335 & 3.1 \\
\hline 3 & 10:00 & 0.18 & $7.5 *$ & $0.61 \%$ & 339336 & 2.06 & 11.4 & 123 & 9.2 & 343 & 3.2 \\
\hline 4 & $10: 30$ & 0.18 & 8.6 & 0.54 & $364 \quad 405$ & 6 & - & - & 9.4 & 341 & 3.4 \\
\hline 5 & & - & . & 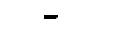 & 329367 & 2.10 & 10.8 & 11 & 9 & 325 & 3 . \\
\hline 7 & $1 ' 2: 00$ & 0.1 & & 0 & $470 \quad 483$ & 6 & 3.0 & 1 & 9 & 330 & 3.1 \\
\hline 8 & $12: 30$ & 0.18 & $9.4 \%$ & $0.49 \%$ & 418442 & 2.10 & 12.2 & 136 & 9.8 & 357 & 3.1 \\
\hline \multicolumn{12}{|c|}{18 jul 1983} \\
\hline 1 & $7: 30$ & 0.30 & 5.1 & 0.90 & 247230 & 2.10 & - & - & 8.2 & 319 & 1.9 \\
\hline 3 & $8: 30$ & 0.15 & 10.3 & 0.45 & 284258 & 2.09 & - & - & $8: 0$ & 300 & 1.9 \\
\hline 4 & 9:00 & 0.20 & 7.7 & 0.60 & 396367 & 2.09 & - & - & 8.5 & 299 & 1.6 \\
\hline 5 & 10:00 & 0.26 & 5.9 & 0.78 & 410380 & 2.09 & - & - & 8.7 & 309 & 2.3 \\
\hline 7 & $10: 20$ & 0.17 & 9.1 & 0.51 & 396355 & 2.17 & - & - & 8.6 & 320 & 2.6 \\
\hline 8 & $10: 45$ & 0.24 & 6.4 & 0.73 & 314267 & Y. 10 & - & - & 8.5 & 319 & 2.1 \\
\hline
\end{tabular}

Tabla 1.- Para cada una de las muestras, determinada por el día y punto de muestreo, se indica la hora de recolección(GMT), la profundidad de visión del disco de Secchi, coeficientes de extinción de la luz y profundidad a que llega el 1\% de la luz, la concentración de clorofila calculada por el método tricromático $(\mathrm{T})$ y por el monocromático según Lorenzen $(\mathrm{M})$, el cociente entre las absorbancias A433/A665, la concentración de $\mathrm{O}_{2}$ y porcentaje de saturación, pH, Eh y el índice de diversidad.

For each sample determined by the date, station number of the site and time of collection, the following parameters are indicated: Secchi disk depth, light extinction coefficient, depth of $1 \%$ light, chlorophyll a concentration by the trichromatic (T) and monochromatic Lorenzen (M) methods, the ratio between absorptions A433/A665, the concentration and percentage of saturation of $\mathrm{O}_{2}$, $\mathrm{pH}$, Eh and diversity index. 
PTOS. MUESTREO
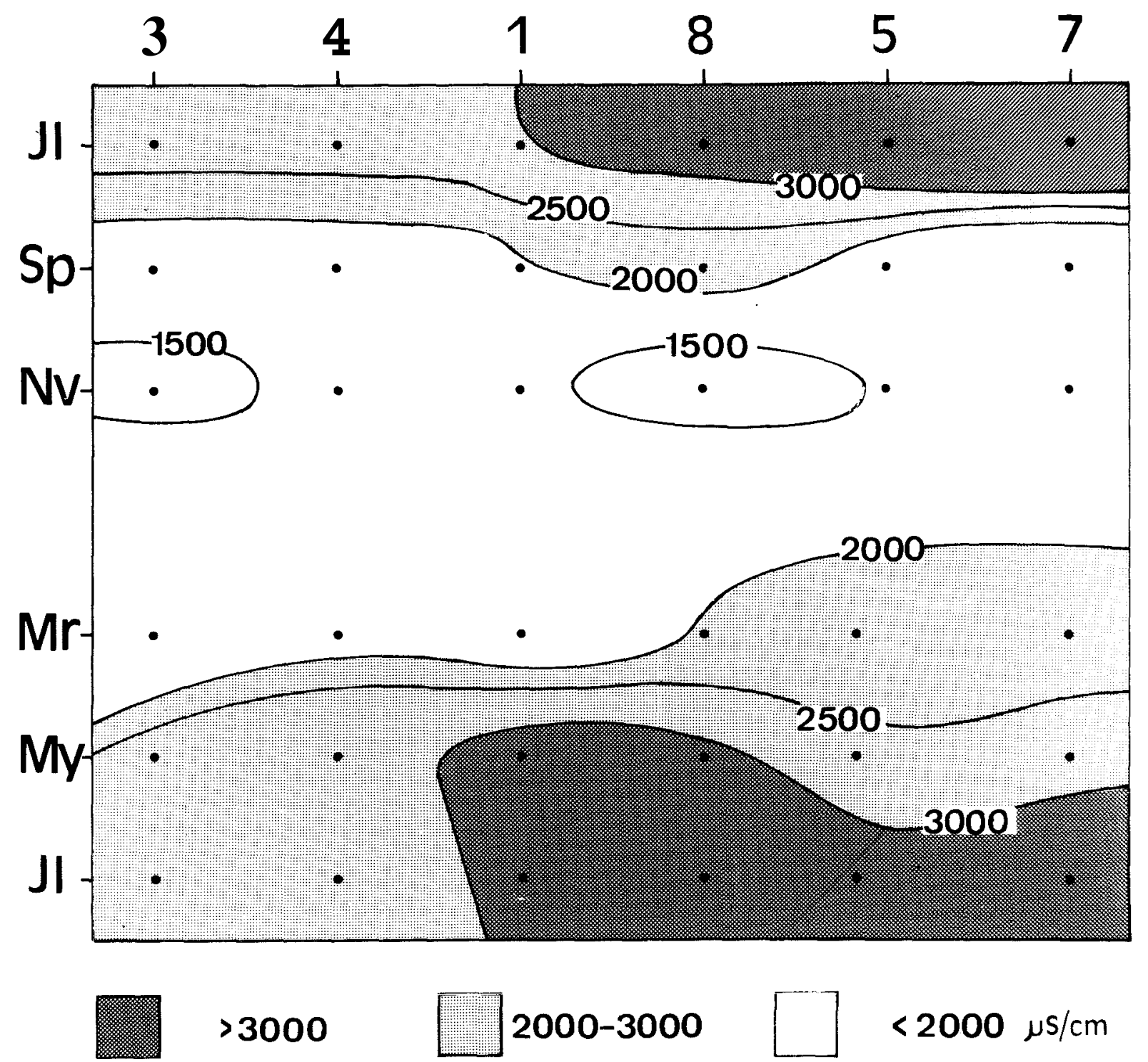

Figura 3.- Distribución de la conductividaden los diferentes puntos de muestreo (abscisas) y meses del año (ordenadas).Los puntos representan las muestrasestudiadas, interpolándose las isolíneas librementeentre sus valores.

Conductivity distribution in the different sampling stations (abscissas)and months (ordinates). Dots represent the sampling points and isoplethsare freely interpolated between their values.

a las inundaciones del 20 de octubre de 1982 antes mencionadas. En una situación normal, el primero de noviembre se cerrarían las compuertas y la conductividad iría aumentando hasta su apertura el primero de enero. En verano también se alcanzarían valores máximos de conductividad, como corresponde a los periodos con las compuertas cerradas, y además, en este caso, por estar sometida la laguna a una evaporación intensa.

\section{Propiedades ópticas del agua y pigmentos fotosintéticos}

La penetración de la luz en el agua es extraordinariamente baja, debido a la enorme densidad de materiales en suspensión, principalmente la población algal y bacteriana y en ocasiones los detritus de materia orgánica y limos. Así, en noviembre de 1982, frente a los valores mínimos de clorofila, aparecen coeficien- 


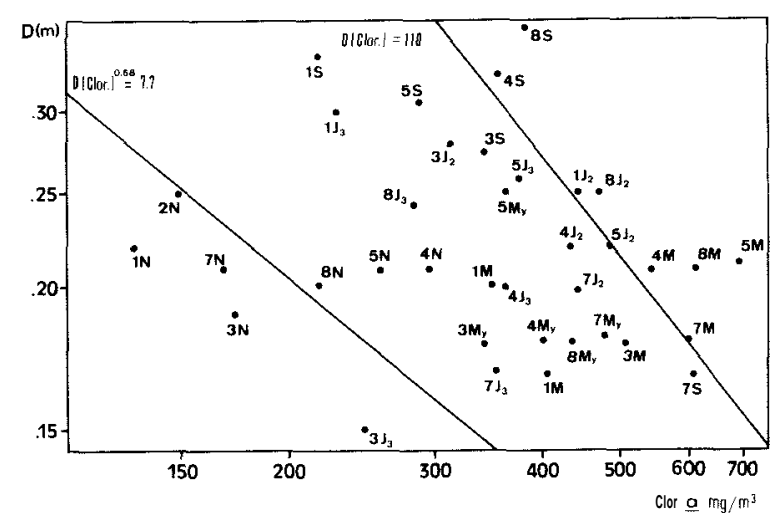

Figura 4.- Relación entre la profundidad de visión del disco de Secchi y la concentración de clorofila a. Las rectas representan las relaciones D [Clor $\left.{ }_{\mathrm{a}}\right]^{0,68}=7,7$ y D [Clor $\left.{ }_{\mathrm{a}}\right]=110$.

Relation between Secchi disk depth and chlorophyll a concentration. The lines represent the relations $\mathrm{D}\left[\mathrm{Clor}_{\mathrm{a}}\right]^{0,68}=$ 7,7 and $\mathrm{D}\left[\mathrm{Clor}_{\mathrm{a}}\right]=110$.

tes de extinción altos, debidos a la presencia de materiales alóctonos transportados por las aguas durante las inundaciones. La profundidad de visión del disco de Secchi (tabla 1) resultó ser poco variable durante todo el periodo estudiado, oscilando alrededor de un valor medio de $23 \mathrm{~cm}$ con una desviación típica de 5 cm. El T.S.I. (Trophic State Index, Shapiro et al, 1975) correspondiente a este valor es de 81.5, índice muy elevado; los TSI más frecuentes en los embalses españoles eutróficos, son del orden de 50 (Margalef $e t$ al, 1977).

El coeficiente de extinción de la luz fue determinado en ocasiones a partir de medidas directas de la penetración de la energía luminosa en el agua efectuadas con un radiómetro, valores que han sido señalados con un asterisco en la tabla 1. Estos valores han sido utilizados para calcular una expresión que muestre la relación entre la profundidad de visión del disco de Secchi (D) y el coeficiente medio de extincion de la luz (n) referido al primer medio metro de la columna de agua. Se acepta que dicho coeficiente es igual a cierta constante dividida por la profundidad de visión,en metros del disco: $\mathrm{n}=\mathrm{c} / \mathrm{D}$. Utilizando esta ecuación para los quince pares de valores disponibles obtuvimos un valor medio de c de 1.545 con una desviación típica de 0.164 . Cuando esta misma relación entre el coeficiente de extinción y la profundidad de visión del disco fue estimada mediante una regresión lineal, se obtuvo un buen ajuste cuyo intervalo de confianza resultó superior al $95 \%\left(\mathrm{~F}_{1,14}=5,41\right)$. La relación evaluada por regresión fue de $\mathrm{n}=1.539 / \mathrm{D}$, de manera que el valor de la constante c coincide prácticamente con la estimada como el valor medio de las razones entre el coeficiente de extinción n y la profundidad de visión del disco D. Este valor de la constante c (1.539) también coincide con el obtenido de la regresión de los datos procedentes de un estudio de 98 muestras de embalses españoles de muy distintos grados de eutrofia (Rull et al, 1984). En la tabla 1 se completaron los restantes valores del coeficiente de extinción no hallados por medida directa, así como la profundidad a la que llega el 1\% de luz incidente, mediante los valores de la profundidad de visión del disco y la relación encontrada por regresión.

La profundidad de visión del disco de Secchi y la concentración de clorofila están ligadas por una función exponencial de valor constante. La representación para la Albufera de dicha relación presenta una cierta dispersión (fig. 4) y además no se ajusta a la función propuesta por Shapiro et al (1975), D[Clor $]^{0.68}=7.7$, puesto que de acuerdo con ella, la profundidad de visión del disco para la correspondiente concentración de clorofila debería ser inferior. Esto es debido a que para concentraciones muy grandes de clorofila la anterior función no es válida, y el producto del Secchi en metros por la concentración de clorofila en $\mathrm{mg} / \mathrm{m}^{3}$ tiende a $110(\mathrm{D}[\mathrm{Clor}]=110)$, cifra límite oara la clorofila. En el mencionado estudio sobre los embalses tampoco se pudo obtener ninguna relación entre D y [Clor], a no ser para valores de $\mathrm{D}$ superiores a $4 \mathrm{~m}$. En la Albufera, los valores correspondientes al mes de noviembre, cuando se registraron las mínimas concentraciones de clorofila se ajustan más a la relación de Shapiro, y se desvían de la tendencia general de la Albufera; estas muestras (puntos 1, 2, 3, 7 y 8) cuyo valor de Secchi es menor que el que les correspondería por su concentración de clorofila, pertenecen a las zonas afectadas por la riada del 20 de octubre de 1982 y presentaban limos en suspensión. La tendencia opuesta más exagerada se da en marzo de 1983 con valores de Secchi mayores respecto a los que les correspondería para su concentración de clorofila. Es como si el alto contenido específico en pigmentos, propio de las poblaciones en crecimiento activo durante el inicio de la primavera, permitiera una mayor transparencia del agua que la correspondiente a sus valores límite. Se puede anotar también que en esta situación, los pigmentos estaban empaquetados fundamentalmente en Clorofíceas y Cianobacterias de mayor tamaño y además corresponden a los mínimos de bacterias filamentosas incoloras (fig. 6) que supondrían, al estar en bajo numero, una considerable disminución de la turbidez del agua para una concentración de clorofila dada.

La variación temporal de la clorofila (fig. 5 y tabla 1) está influenciada por la hidrodinámica de la laguna. En septiembre, cuando se abren las compuertas, se observa una disminución general de la clorofila respecto de los valores de verano, asociada a un aumento de la transparencia del agua en toda la Albufera, excepto en el punto 7 , que experimentó un creci- 


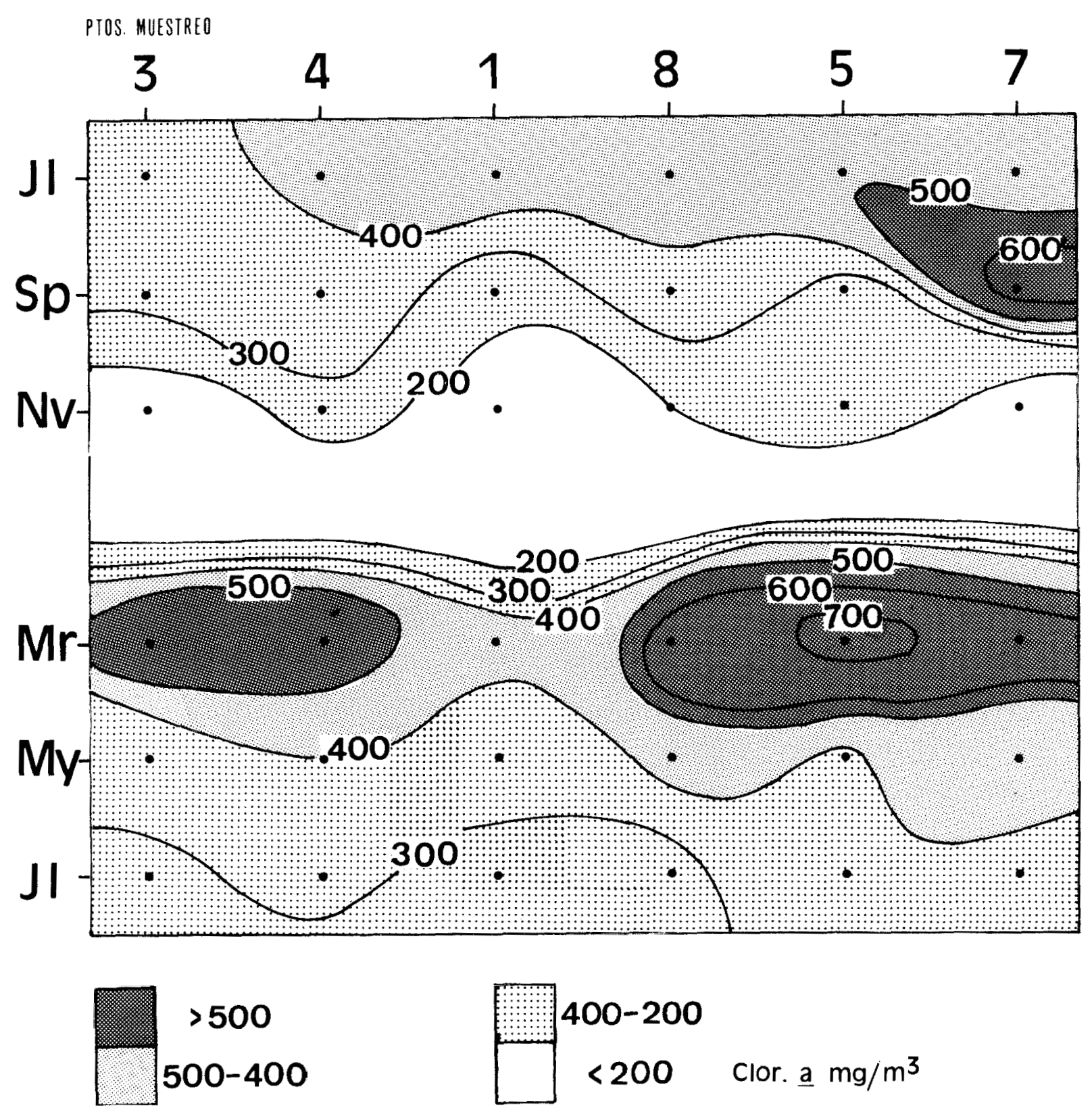

Figura 5.- Distribución de la concentración de clorofila a determinada por el método de Lorenzen en los diferentes puntos de muestreo (abscisas)y meses del año (ordenadas).Los puntos representan las muestras estudiadas, interpolándose las isolíneas libremente entre sus valores.

Concentration of chlorophyll $a$ distribution evaluated by Lorenzen method in the different samplig stations (abscisas) and months (ordinates). Dots represent the sampling points and isoplethsare freely interpolated between their values.

miento muy marcado de diatomeas. Esta disminución coincidió con el descenso de la salinidad, lo que nos confirma su causa en la entrada de agua procedente de los arrozales, que diluyó y perturbo el crecimiento del fitoplancton.
La proporción de feofitina, respecto al total de pigmentos fotosinteticos, varía considerablemente segun la época del año y el punto de la Albufera de donde proceda la muestra. Esta proporción oscila entre valores inferiores al $5 \%$, para las poblaciones en pleno 
PUNTO 1
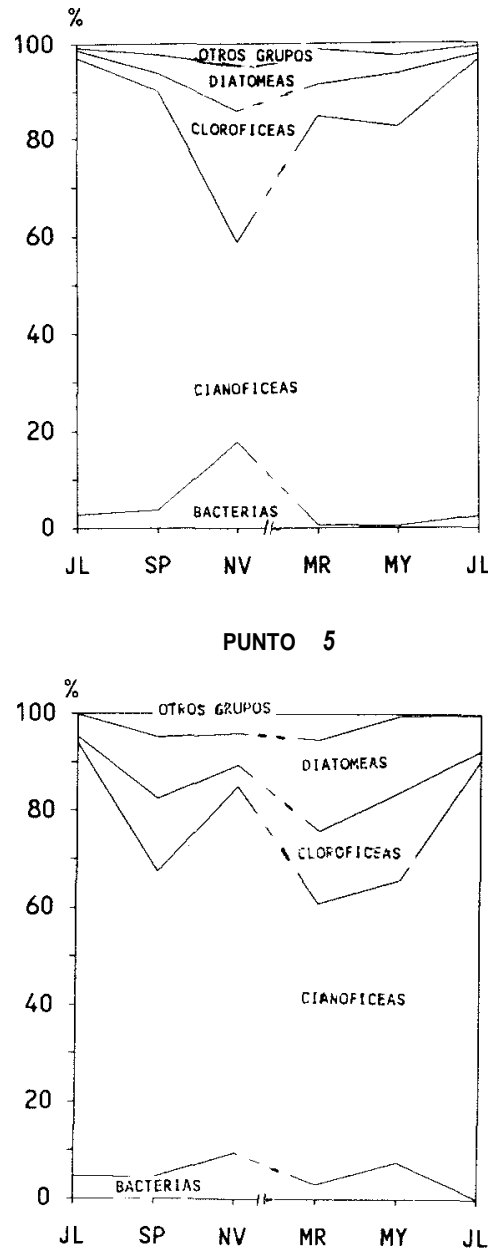

PUNTO 3

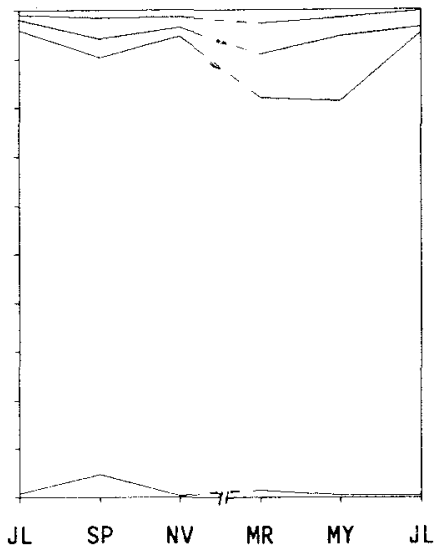

PUNTO 7

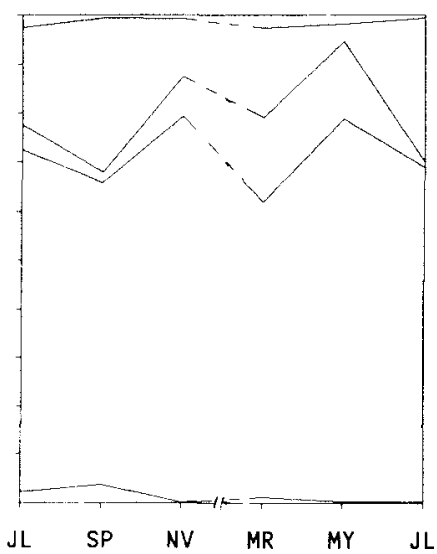

PUNTO 4
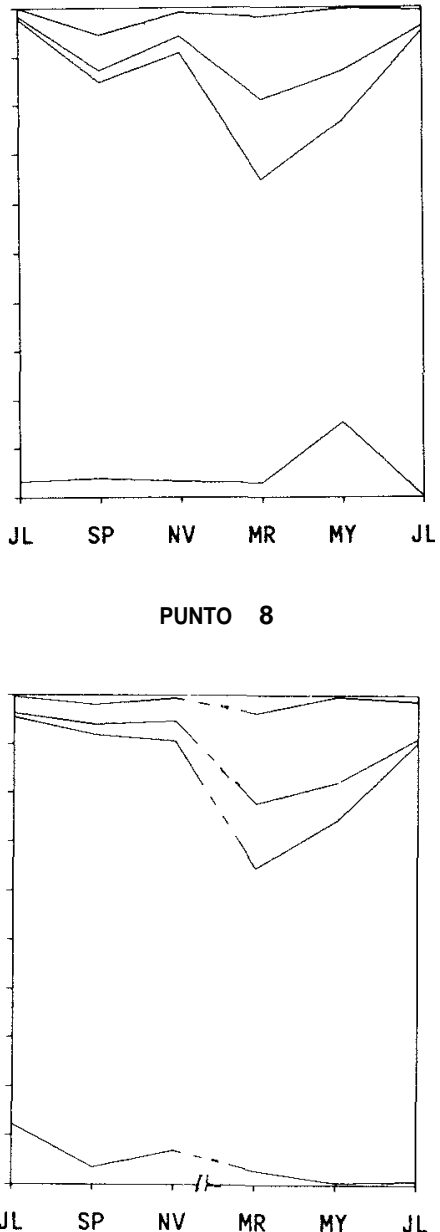

Figura 6.- Variación temporal de los porcentajes de los diferentes grupos planctónicos en cada uno de los puntos de muestreo, representados de abajo a arriba en el siguiente orden: bacterias (filamentosas envainadas y deslizantes, Blastocaulis-Planctomyces y Pasteuria), cianobacterias, cloroficeas, diatomeas y los restantes grupos.

Temporal variation of the percentages of the different planktonic groups in each sampling site, represented from down to top in the following order: bacteria (sheated and gliding filaments. Blastocaulis-Planctomyces and Pasteuria), cyanobacteria, chlorophyta, diatoms and the rest of the groups.

crecimiento, o superiores al $25 \%$, correspondiente al declive y muerte del fitoplancton, situación que se produce en el mes de septiembre. En la tabla 1, comparando las cantidades de clorofila calculadas aplicando el método tricromático (columna señalada con T) con las correspondientes halladas por el método monocromático deducida la feofitina (señalada con M) que son algo inferiores, podemos evaluar el porcentaje de feofitinas, relacionable también con el índice de Margalef (A433/A665) y el estado fisiológico del fitoplancton.

Cuando, la gran densidad de población de las espe- cies de Oscillatoria decae y se favorece el crecimiento de otros grupos, se produce un aumento del índice de diversidad (tabla 1). Al inicio de la primavera y tras la consiguiente interrupción del flujo por el cierre de las compuertas, se alcanzan los valores máximos de diversidad. Los valores mínimos de este índice se dieron en noviembre, justo después de las inundaciones de 1982.

Por otra parte, la distribución espacial de la clorofila muestra una tendencia a presentar los valores máximos en las estaciones del Norte, puntos 5 y 7 (fig. 5 , tabla 1), que son las más contaminadas, siendo gene- 
ral la existencia de máximos alternativos de la concentración de clorofila entre dichas estaciones.

\section{Oxígeno, pH y potencial de oxidorreducción}

La concentración de oxígeno (tabla 1) presenta unos mínimos claros en verano, consecuencia de su bajo coeficiente de solubilidad a las altas temperaturas durante esta época del año. En superficie a mediodía está por encima de los valores de saturación como corresponde a los lagos hipertróficos, excepto durante el mes de julio, cuando la temperatura elevada incrementa la tasa respiratoria de los organismos y también la actividad bacteriana. La gran variación de unos puntos a otros tiene su correspondencia, en primer lugar con la concentración de clorofila (fig. 5) y en segundo lugar con la hora del muestreo (tabla 1), que oscilaba entre las 7 y las 13 horas (GMT). Algunos valores anormalmente bajos para la concentración de oxígeno disuelto se deben a la existencia de fuertes vertidos de materia orgánica en las proximidades del punto de muestreo (punto 7, Barranc de Massanassa).

Al igual que el oxígeno, el pH (tabla 1) depende de la actividad fotosintética sobre todo debido a la escasa reserva alcalina de la Albufera, con máximos en los meses de marzo y mayo y en las zonas con mayor concentración de clorofila, puntos 5 y 7 (fig. 5). La reserva alcalina es precipitada por las continuas entradas de fosfatos y por el $\mathrm{pH}$ elevado, que con frecuencia presenta valores mayores que 9 unidades, consecuencia de la actividad fotosintética. Así, se entra en un cúmulo de circunstancias, donde la falta de reserva alcalina permite el aumento del $\mathrm{pH}$, que a su vez promueve la precipitación de la alcalinidad en forma de carbonatos insolubles. Además, una vez se alcanzan valores bajos de alcalinidad, se disminuye la precipitación del fósforo que queda disponible para el mantenimiento de la actividad de grandes densidades de fitoplancton.

El potencial de oxidorreducción (tabla 1) es bastante bajo, teniendo en cuenta que un valor de $200 \mathrm{mV}$ se considera en el límite entre la zona oxidada y reducida del sedimento. Los valores de potencial fueron mínimos en verano y en el punto de muestreo numero 5 , como corresponde a los mínimos de oxígeno y a las mayores concentraciones de materia orgánica, y todo ello es coherente con otros datos de campo. como el elevado $\mathrm{pH}$ producto de la actividad fotosintética (tabla 1, fig. 5). Pero además, esta actividad fotosintética supone excreción de productos orgánicos reducidos (D.O.C.), con lo que también se está favoreciendo el descenso del potencial de oxidorreducción.

\section{Algas y bacterias planctónicas}

Este ambiente hipertrófico propicia unas comunidades planctónicas próximas a las de los sistemas altamente contaminados por el vertido de aguas residuales muy ricas en materia orgánica. En primer lugar, destaca la relativa abundancia de una sene de géneros de bacterias planctónicas (fig. 6) pertenecientes a los siguientes grupos descritos en Starr et al. (1981): 1) bacterias deslizantes de los géneros Flexithrix, Thoxothrix, Herpethosyphon y Flexibacter, 2) bacterias envainadas del género Haliscomenobacter y 3) bacterias prostecadas de los géneros Ancalomicrobium, Blastocaulis-Planctomyces, Hyphomicrobium, Pasteuria, Seliberia, etc. Todas ellas son quimioheterotrofas que obtienen su energía de la descomposición de compuestos orgánicos, debiéndose resaltar la capacidad celulolítica de algunas de ellas y también su presencia frecuente en los digestores de las depuradoras de aguas residuales.

El grupo de organismos autotrofos más importante en el plancton de la Albufera es el de las Cianobacterias, como es de esperar de acuerdo con el elevado grado de eutrofia que presentan sus aguas, siendo especialmente abundantes las del grupo Oscillatoria redekei (0. redekei, y 0 . limnetica), es decir, las constituidas por filamentos finos (anchura entre 1.2 y 1.5 $\boldsymbol{\mu} \mathrm{m})$. También es abundante ocasionalmente Oscillatoria agardhii, especie muy vacuolada, que en ocasiones produce acúmulos flotantes en zonas resguardadas de la laguna, donde la acción del viento y circulación del agua son reducidas. También fue abundante Lyngbya contorta, y Lymgbya limnetica, estando las demás especies de Cianobactenas y de otros grupos algales en mucha menor proporción. En total se identificaron noventa y nueve especies fitoplanctónicas siendo el grupo más diverso el de las Cloroficeas con cuarenta y ocho especies, las Bacilariofíceas con veintisiete y las Cianofíceas con quince. Además se encontraron seis especies de Euglenales, dos Criptoficeas y un Dinoflagelado.

El estudio de la distribución espaciotemporal (fig. 6) ha dado la máxima cantidad de Bacilariofíceas en el punto 7 al final del verano; de las Cianobacterias en verano y otoño por toda la Albufera salvo el punto 7 y las Cloroficeas en primavera, especialmente en puntos del oeste y norte.

En la figura 6 se representa para cada una de las localidades de muestreo, la frecuencia relativa de las bacterias planctónicas y cada uno de los principales grupos algales del plancton, durante el ciclo anual. Se observa la dominancia general de Cianobacterias durante todo el año, llegando a totalizar en ocasiones más del 90\% del fitoplancton, excepto en la zona norte de la laguna (punto 7), donde su proporción es del $75 \%$. En primavera se produce una disminución de su 
incidencia con un mínimo en marzo coincidente también con una disminución de los grupos bacterianos heterotrofos.

Por último, se ha calculado la diversidad con el índice de Shannon (tabla 1) presentándose la máxima a finales de invierno en el norte, noroeste y centro, y a finales de primavera en el oeste y noroeste, con valores alrededor de 3.5. La mínima diversidad se produce en verano, especialmente en julio de 1983 y al oeste (punto 4), con valores de 1.6. En general, los puntos del norte (puntos 5 y 7) presentan alternativamente, en las distintas épocas, los mayores valores de diversidad.

\section{CONCLUSIONES}

La variabilidad en la distribución espaciotemporal de los parámetros físicoquímicos está ligada al flujo de agua que circula por la Albufera, en gran parte determinada por el hombre y la climatología. La heterogeneidad espacial de las comunidades fitoplanctónicas se pone de manifiesto por la distribución de las especies, distinguiéndose por lo menos dos comunidades diferentes, la correspondiente a las estaciones del norte (de la 5 a la 7) con un porcentaje mayor de Bacilarioficeas, y las correspondientes al resto de la laguna.

Este estudio demuestra que la Albufera de Valencia es una laguna extremadamente contaminada. Así lo evidencian los altos valores de la concentración de clorofila en sus aguas. Además, por sumarse al proceso normal de eutrofización por aportes de nutrientes inorgánicos, el vertido masivo de materia orgánica soluble y particulada procedente de aguas residuales no depuradas, se favorece la implantación de poblaciones bacterianas heterótrofas, en su mayoría formas planctónicas filamentosas, envainadas y prostecadas, algunas de ellas relacionadas en cuanto a su hábitat con las especies típicas de las plantas de depuración de aguas residuales. No se han considerado en este estudio el importante número de formas bacterianas heterotrofas bacilares, cocáceas, espirales y espiroquetales, presentes en todas las muestras, así como la posible presencia de patógenos potenciales entre estos grupos bacterianos.

\section{BIBLIOGRAFIA}

Desikachary, T.V., 1959. Cyanophyta. Indian Council of Agricultura1 Research. Nueva Delhi.

García, M.P., E. Vicente y M.R. Miracle, 1984. Sucesión estacional del fitoplancton en la Albufera de Valencia. Anales de Biología 2 (s.e. 2): 91-100.

Germain, H. 1981. Flore des Diatomées. S.N. Ed. Boubée. Paris, pp. 444.

Huber-Pestalozzi, G. 1938, 1941, 1942, 1955, 1961, 1968, 1972,1982,1983. Das phytoplankton des Süsswassers. Band XVI. Teil 1-8. E. Scheweizerbart'sche Verlagsbuchhandlung (Erwin Nagele).Stuttgart.

Lorenzen, C.J. 1967. Determination of chlorophyll and pheopigments: spectrophotometricequations. Limnol Oceanogr. 12: 343-348.

Margalef, R., D. Planas, J. Armengol, A. Vidal, N. Prat, A. Guiset, J. Toja y M. Estrada, 1977. Limnologia de los embalses españoles. Ministerio de Obras Públicas. Publicación 123. Madrid.

Miracle, M.R., M.P. García y E. Vicente. 1984. Heterogeneidad espacial de las comunidades fitoplanctónicas de la Albufera de Valencia. Limnetica 1: 20-31.

Oltra, R. y M.R. Miracle. 1984. Comunidades zooplanctónicas de la Albufera de Valencia. Limnética 1: 51-61.

Roselló, V.M. 1979. Els espais albuferencs del País Valencia. Acta Geológica Hispánica, 14: 487-493.

Rull, V., T. Vegas y J. Navarro. 1984. Extinción de la luz en los embalses españoles. Relaciones con la concentración de clorofila y las partículas en suspensión. Oecologia aquatica, 7: 25-35.

Serra, M., M.R. Miracle y E. Vicente, 1984. Interrelaciones entre los principales parámetros limnológicos de la Albufera de Valencia. Limnetica 1:9-19.

Shapiro, J., J.B. Lundquist and R.E. Carlson. 1975. Involving the public in Limnology. An approach to communication. Verh. Internat. Verein. Limnol. 19: 866-874.

Shoaf, W.T. and B.W. Lium. 1976. Improved extraction of chlorophyll $a$ and $b$ from algae using dimethyl sulfoxide. Limnol. Oceanogr. 21:926-928.

Starr, M.P., H. Stolp, H.G. Trüper, A. Balows and H.G. Schelegel. 1981. The Prokaryotes. Vol. I. Spnnger Verlag. Berlín. pp. 1.102.

Strickland, J.D.H. \& T.R. Parsons. 1972. A practical Handbook of seawater analysis. Bull. Fish. Res. Bd. Canada 167. pp. 311.

Wetzel, R.G. and G.E. Likens. 1979. Limnological Analyses. W.B. Saunders Company. Philadelphia,PA. pp. 358. 